\title{
Correlation Between Clinical Symptoms Of Various Colorectal Diseases And Colonoscopic Findings \\ Kidwai $R^{1}$, Sharma $A^{2}$
}

\begin{abstract}
Background: About $30 \%$ of patients presenting to surgical outpatient department has lower gastrointestinal (LGI) symptoms. Colonoscopy is a low risk and at the same time investigation of choice in these patients which allows visualization of the entire colon and the terminal portion of ileum. This study was done to find out the diagnostic accuracy of colonoscopy in relation to the clinical symptoms of the disease. Methods: This was a prospective, hospital based study from February 2014 to March 2019 , carried out at Nepalgunj Medical College and Teaching Hospital. The colonoscopic diagnosis was compared with the clinical symptoms and further confirmed with histological examination. Results: 341 patients underwent colonoscopy. There were 234 (68.62\%) males and 107 (31.37\%) females with the male to female ratio of 2.18: 1 . The age ranged from 16 to 81 with the mean age of $59.63 \pm 10.37$. The most common presenting symptom was per rectal bleeding $(40.34 \%)$ the after were alteration in bowel habit (17.30\%), constipation (12.90\%), hematochezia (11.43\%). The least common indication for colonoscopy was unexplained anemia. Haemorrhoids were the most common findings consisting $32.55 \%$. In $19.94 \%$ it was normal. Majority had various inflammatory conditions, among them $10.85 \%$ had proctocolitis, $2.34 \%$ were suspected to have ulcerative colitis. There were $17(4.98 \%)$ patients with colonic and $13(3.18 \%)$ with rectal carcinoma. $10.55 \%$ had colorectal polyps. Out of 111 patients suspected to have hemorrhoids clinically 102 had same findings on colonoscopy. Similarly 34 patients presenting with chronic diarrhea with bleeding and 59 with alteration in bowel habit where inflammatory conditions were suspected had similar findings on colonoscopy in 29 and 34 patients respectively. Similarly the suspicion of malignancy on clinical basis was also correlated on colonoscopy. The inflammatory conditions diagnosed on colonoscopy were confirmed in $\mathbf{8 5 . 0 4} \%$ by histology. Similarly malignancy and the presence of polyps diagnosed on colonoscopy were confirmed by histology in $97.05 \%$ and in $97.22 \%$ cases respectively. Conclusion: Colonoscopy is a safe and effective investigation to diagnose various colorectal conditions. There was a correlation between the clinical symptoms and the colonoscopic diagnosis especially in conditions like inflammatory and neoplastic colorectal diseases. When combined with histology the diagnostic accuracy can be near $100 \%$ in conditions like inflammatory and benign or malignant diseases.
\end{abstract}

Key words: Colonoscopy, Clinical symptoms, Histopathology

\section{INTRODUCTION}

Various conditions like neoplastic, inflammatory, infectious and vascular malformations can affect the colon and rectum. The clinical presentation of these conditions is different but many times the symptoms may be common for different diseases. Colonoscopy is now accepted as a gold standard modality for the diagnosis of different colorectal conditions. Colonoscopy has not only revolutionized the diagnostic aspect

1. Dr. Roman Kidwai

2. Dr. Anup Sharma

\section{Address for Correspondence:}

Dr. Roman Kidwai

Department of Surgery

Nepalgunj Medical College \& Teaching Hospital

Nepalgunj, Banke

Email:romankidwai1@gmail.com of colorectal diseases but also the therapeutic aspect. Conditions like polyps and lower gastrointestinal (GI) bleeding can be treated by colonoscopy which required a surgical intervention in the past ${ }^{1}$.

Entire colon and the terminal part of the ileum can be visualized with the help of colonoscopy. One of the greatest advantages of colonoscopy is to take biopsy for histological examination. The indications of colonoscopy are lower GI bleeding, alteration in bowel habit, constipation, chronic diarrhea etc. ${ }^{2}$. presence of fecal occult blood is a strong indicator of colonoscopy ${ }^{3}$ colonic polyps are frequently found in colonoscopy and polypectomy is a routine a routine part of colonoscopy ${ }^{4}$.

This study aimed to find out the diagnostic accuracy of colonoscopy in relation to the clinical symptoms of the disease. The accuracy was confirmed by histological diagnosis.

\section{METHODS AND MATERIALS}

It was a prospective, hospital based study from February 2014 to March 2019, carried out at Nepalgunj Medical College and 
Teaching Hospital, department of surgery. All patients who underwent colonoscopy were included. Patients below 16 years age and patients with severe cardiopulmonary disease were excluded. Informed consent was taken from the patients and ethical clearance was also taken from the ethical board. Bowel preparation was done with polyethelene glycol. Colonoscopy was done without sedation. Sedation was given only when needed. The procedure was performed using a fibre optic video colonoscope (Fujinon). Biopsy was taken as per the requirement. The colonoscopic findings were compared with the clinical symptoms to find out the accuracy of diagnosis and further confirmed with histological diagnosis.

\section{RESULTS}

341 patients underwent colonoscopy during the study period. There were 234 (68.62\%) males and 107 (31.37\%) females with the male to female ratio of 2.18: 1 . The age ranged from 16 to 81 with the mean age of $59.63 \pm 10.37$. The clinical symptoms are showed in table I.

\begin{tabular}{|c|c|}
\hline Clinical symptoms & No. of patients (\%) \\
\hline Per rectal bleeding & $141(40.34 \%)$ \\
\hline Alteration in bowel habit & $59(17.30 \%)$ \\
\hline Constipation & $44(12.90 \%)$ \\
\hline hematochazia & $39(11.43 \%)$ \\
\hline Chronic diarrhea with bleeding & $34(9.97 \%)$ \\
\hline Abdominal masses & $13(3.81 \%)$ \\
\hline Unexplained anemia & $11(3.22 \%)$ \\
\hline
\end{tabular}

Table I: Clinical symptoms

Hemorrhoids were the most common finding followed by inflammatory conditions and then were the neoplastic lesions (Table II)

\begin{tabular}{|c|c|}
\hline Colonoscopic Finding & No. of patients (\%) \\
\hline Haemorrhoids & $111(32.55 \%)$ \\
\hline Normal & $68(19.94 \%)$ \\
\hline Colorectal polyps & $36(10.55 \%)$ \\
\hline Proctocolitis & $37(10.85 \%)$ \\
\hline Colitis & $29(8.50 \%)$ \\
\hline Proctitis & $19(5.57 \%)$ \\
\hline Carcinoma colon & $17(4.98 \%)$ \\
\hline Carcinoma rectum & $13(3.81 \%)$ \\
\hline Tuberculosis & $11(3.22)$ \\
\hline Ulcerative colitis & $8(2.34 \%)$ \\
\hline Carcinoma anal canal & $4(1.17 \%)$ \\
\hline
\end{tabular}

Table II: Colonoscopic finding
There were 141 patients with per rectal bleeding. Among them 102 (91.81\%) had hemorrhoids. Among the patients with alteration in bowel habit, in $36(61.01 \%)$ the findings were suggestive of various inflammatory diseases, in 6 (16.66\%) suggestive of malignancy and in 17 the colonoscopy was unremarkable. 39 (88.63\%) patients with constipation had normal colonoscopy, 5 (11.36\%) had features of colorectal malignancy. Those who presented with hematochezia, 21 (53.84\%) had inflammatory diseases and 7 (17.94\%) had features of colorectal cancer. The colonoscopic finding of patients with chronic diarrhea with bleeding was also suggestive of inflammatory (70.58\%) and colorectal cancers (8.82\%). Eleven patients were suspected to have intestinal tuberculosis on colonoscopy. Among them 6 (54.54\%) presented with abdominal mass. (Table III)

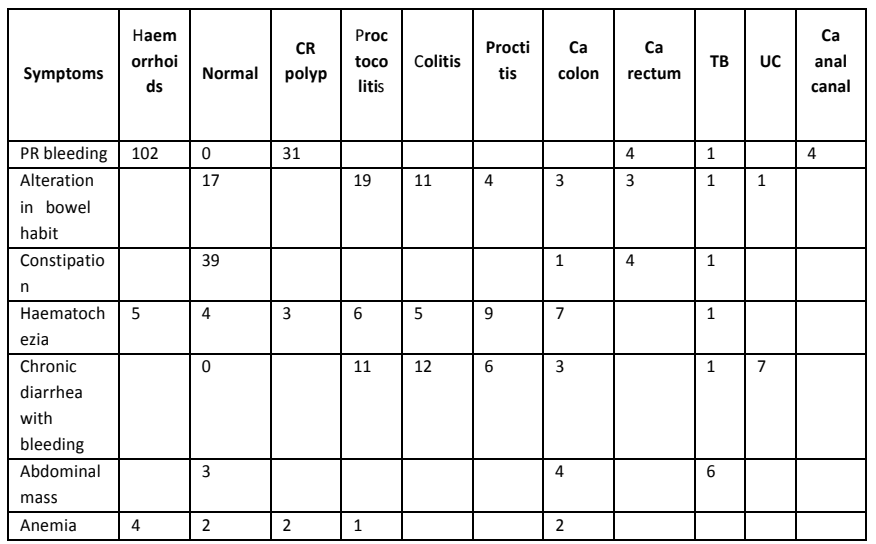

CR polyp: colorectal polyp, TB: tuberculosis, UC: ulcerative colitis Table III: Correlation of clinical symptoms with colonoscopy findings

\begin{tabular}{|c|c|}
\hline Histology & No. of patients \\
\hline $\begin{array}{c}\text { Non specific inflammatory } \\
\text { diseases }\end{array}$ & $91(52.90 \%)$ \\
\hline Juvenile polyp & $17(9.88 \%)$ \\
\hline Ca colon (adenocarcinoma) & $16(9.30 \%)$ \\
\hline Ca rectum (adenocarcinoma) & $13(7.55 \%)$ \\
\hline Adenomatous polyp & $10(5.81 \%)$ \\
\hline Hamartomatous polyp & $8(4.65 \%)$ \\
\hline Tuberculosis & $8((4.65 \%)$ \\
\hline Ulcerative colitis & $5(2.90 \%)$ \\
\hline $\begin{array}{c}\text { Ca anal canal (squamous cell } \\
\text { carcinoma) }\end{array}$ & $4(2.32 \%)$ \\
\hline
\end{tabular}

Table IV: Histopathological examination was done in 172 patients with various findings

Clinical findings were correlated with histological findings. Colonoscopy overall could diagnose the inflammatory condition in $85.04 \%$. Similarly malignancy and the presence of polyp could also be suspected in $97.05 \%$ and in $97.22 \%$ cases respectively. 


\section{DISCUSSION}

Colonoscopy is the investigation of choice in the diagnosis of the disease affecting the colon and rectum. The most common indication for colonoscopy was per rectal bleeding followed by alteration in bowel habit and constipation. There was a male dominance which is in consistency with other studies ${ }^{5}$. The mean age in this study was 59.63. The relatively younger age group may be explained by the commonest findings being haemorrhoids which occur commonly after the fifth decade of life ${ }^{6}$. The colonoscopy was normal in 68 (19.94\%). The rate of normal findings were higher in the beginning when it was started and with time, started decreasing which may be due to improvement in patients selection. Other similar studies also showed same data ${ }^{7}$.

The most common finding was haemorrhoids, followed by nonspecific inflammatory bowel disease, colorectal polyps and colorectal carcinomas. The prevalence of haemorrhoids was similar to other studies ${ }^{7,8}$. The second common finding was nonspecific inflammatory bowel disease. Many of them were of infective etiology and resolved with antibiotics, antiamoebic and antihelminthics.

The occurrence of colorectal polyps is generally thought to be lower in this part of the world and in this series the colorectal polyps were third common finding commonly found in younger patients. We found a prevalence of $10.55 \%$ which is in consistent with other studies ${ }^{9}$. All of them were less than five in numbers and none showed any morphologic or histologic characteristics of any syndromic colorectal diseases. The incidence of colorectal cancer in Nepal is uncertain. In our study it was found to be in $9.97 \%$ patients.

When the clinical symptoms were correlated with colonoscopic findings, it was found that the findings were correlated in patients with per rectal bleeding, alteration in bowel habit, hematochezia and chronic diarrhea with bleeding. Haemorrhoids were common in patients who presented with fresh bleeding during defecation (PR bleeding), which is the common symptom of haemorrhoids. Similarly when symptoms like altered bowel habit, chronic diarrhea and hematochezia underwent colonoscopy, inflammatory diseases and malignant lesions were common findings. Colonoscopy could detect colorectal polyps in almost all patients. Overall colonoscopy could identify the pathology depending on the symptoms but could not differentiate between specific inflammatory disease like ulcerative colitis or nonspecific inflammatory disease. Similarly polyps were easily diagnosed but colonoscopy was not able to categorize the type. Depending on clinical symptoms malignancy could be suspected on colonoscopy but cannot be confirmed.

Overall 107 patients had findings suggestive of inflammatory bowel disease on colonoscopy among them 91 had nonspecific inflammation, 8 patients had tuberculosis and 5 had ulcerative colitis. Only 3 patients where inflammatory disease was suspected didn't have inflammation on histology. Nonspecific inflammation is commonest ${ }^{10}$. Similarly malignant lesion on colonoscopy were proved to be malignancy in $97.05 \%$. The polyps which were diagnosed on colonoscopy turned out to be different types of polyps on histology also.

\section{CONCLUSION}

Colonoscopy is an important modality of investigation in patients with lower gastrointestinal symptoms. The diagnostic yield is significant with an added advantage of biopsy. The diagnostic accuracy when compared with clinical symptoms was also high, specially for malignancy, colorectal polyps and inflammatory conditions and when adjuncted by histology, diagnostic yield may reach near $100 \%$ in conditions like polyps, colorectal cancers, and in differentiating between specific (e.g. ulcerative colitis) and nonspecific inflammatory diseases.

\section{REFERENCES}

1. Cappell MS, Friedel D. The role of sigmoidoscopy and colonoscopy in the diagnosis and management of lower gastrointestinal disorders: endoscopic findings, therapy and complication. Med Clin North Am 2002 Nov;86:125388

2. Singh H. Nugent Z, Mahamud SM,Bernstein CN. Surgical resection of hepatic metastatis from colorectal cancers: $A$ systematic review of published studies. Am J Gastroenterol 2010; 105:663-73.

3. Berner $\mathrm{H}$, Hoffmeister $\mathrm{M}$, Arndt V, Haug U. protection from right and left sided colorectal neoplasms after colonoscopy: Population based study. J natl Cancer Inst 2010; 102:89-95.

4. Atkin WS, Edwards R, Kralj-Hans I, Hart AR. Once-only flexible sigmoidoscopy screening in prevention of colorectal cancers: A multicentric randomized controlled trial. Lancet 2010;375:1624-33.

5. Katon RM. Experimental control of gastrointestinal hemorrhage via the endoscope: A new era dawns. Gastroenterology 1987; 100:74-7.

6. Lee JH, Kim HE, Kang JH, Shin JY, Song YM. Factors associated with hemorrhoids in korean adults: korean national health and nutrition examination survey. Korean J Fam Med 2014; 35: 227-236. 
7. Alatise OI, Arigbabu AO, Agbakwuru EA, Lawal OO, Ndububa DA, Ojo OS. Spectrum of colonoscopy findings in Ile-Ife Nigeria. Niger Postgrad Med J. 2012 Dec; 19: 219-24.

8. Riss S, Weiser FA, Riss T, Schwameis K, Mittlböck M, Stift A. Haemorrhoids and quality of life. Colorectal Dis 2011 Apr; 13:48-52.

9. Ogutu EO, Okoth FA, Lule GN. Colonoscopic findings in Kenyan African patients. East Afr Med J. 1998; 75:540-3.

10. Deshpande V, Hsu M, Kumarasinghe MP, et al. The clinical significance of incidental chronic colitis: a study of 17 cases. Am J SurgPathol 2010; 34(4):463-9 